\title{
Health promotion outcomes associated with a community-based program to reduce pesticide-related risks among small farm households
}

\author{
FADYA A. OROZCO ${ }^{1 *}$, DONALD C. COLE ${ }^{2}$, SELAHADIN IBRAHIM ${ }^{2,3}$ \\ and SUSITHA WANIGARATNE ${ }^{4}$ \\ ${ }^{1}$ Federal University of Bahia, Instituto de Saúde Coletiva, Brazil ${ }^{2}$ Dalla Lana School of Public Health, \\ University of Toronto, Ontario, Canada ${ }^{3}$ Institute for Work \& Health, Ontario, Canada ${ }^{4}$ Cancer Care \\ Ontario, Ontario, Canada \\ *Corresponding author. E-mail: fady5o@yahoo.es
}

\section{SUMMARY}

A range of determinants at multiple socio-ecological levels operate in small farm households' use and handling of hazardous pesticides, suggesting the need for integrated health and agriculture promotion approaches. The aim is to assess changes in health promotion outcomes relevant to highly hazardous pesticide use associated with a multicomponent community program. A longitudinal evaluation design using mixed methods was employed in 18 agricultural communities in Ecuador. Over a 7-month period, health education and agricultural interventions focused upon: health risks associated with hazardous pesticides, more adequate use and handling of pesticides, and better crop management techniques. Data collection included field forms, focus groups, structured observations and repeat surveys. In the qualitative analysis, communities were compared by extent of leadership and involvement with the interventions. For the quantitative
\end{abstract}

analysis, hypothesized paths were constructed including factors relevant to pesticide-related practices and use. Testing involved gender-role stratified (household and crop manager) multivariable regression models. Information on pesticide health impacts and the pesticide use and handling, shared in focus groups, showed substantial improvement, as a result of health promotion activities though people were still observed to engage in risky practices in the field. In path models, community leadership and intervention intensity lead to changes in the household managers' pesticide-related knowledge and practices and to reduction in farm use of hazardous pesticides (both significant, $p<0.05$ ). Integrated, community programs can promote pesticide-related risk reduction among small farm households. Changing practices in the use and management of pesticides among crop managers appears limited by deeper structural and cultural factors.

Key words: intervention evaluation; environmental health promotion; rural health; multiple strategies

\section{INTRODUCTION}

Hazardous pesticide use remains an important environmental health challenge for small farm households in lower and middle income countries (Orozco et al., 2009). A range of determinants at multiple ecological levels (McLeroy et al., 1988) are implicated in small-scale farmers' inappropriate use and inadequate handling of hazardous pesticides (Table 1).

With such a complex set of determinants, efforts to change use and practices require a focus beyond individual behavior (Keifer, 2000; Perry and Layde, 2003; Janhong et al., 2005). Integrated health promotion approaches, 
Table 1: Main determinants of inappropriate use and inadequate handling of hazardous pesticides among small scale farmers, by ecological level

\begin{tabular}{ll}
\hline $\begin{array}{l}\text { Ecological } \\
\text { level }\end{array}$ & Determinants \\
\hline Intrapersonal & $\begin{array}{c}\text { Insufficient knowledge of health impacts } \\
\text { of pesticides, contamination pathways } \\
\text { and risk reduction options } \\
\text { Limited range of skills in crop } \\
\text { management }\end{array}$ \\
& and health risk perceptions influence \\
& practices \\
& Sharing of concerns about health impacts \\
& of pesticides among farming \\
& households (both nuclear and \\
extended families) & Information dissemination on alternative \\
agricultural approaches among farm \\
household networks
\end{tabular}

${ }^{\mathrm{a}}$ Cole et al. (2002), Hruska and Corriols (2002), Cole et al. (2007) and Mancini et al. (2009). ${ }^{\mathrm{b}}$ Crissman et al. (1998), Buranatrevedh and Sweatsriskul (2005), Rodriguez et al.

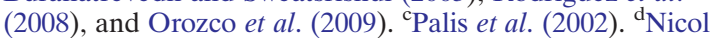
and Kennedy (2008), Arcury et al. (2009) and Orozco et al. (2009). ${ }^{\mathrm{E}}$ Erbaugh et al. (2003), Hamilton et al. (2003), Luther et al. (2005), Peres et al. (2006), Bantilan and Padmaja (2008) and Orozco et al. (2009). ${ }^{\mathrm{f}}$ Orozco and Cole (forthcoming). ${ }^{\mathrm{g}}$ Murray and Taylor (2000),

Konradsen et al. (2003) and Roberts et al. (2003).

spanning levels and the health and agriculture sectors are required (Butterfoss et al., 1996; Cole et al., 2002; Buranatrevedh and Sweatsriskul, 2005; Quandt et al., 2006; Strong et al., 2008). These aim to transform the social environment (Poole, 1997; Austin et al., 2001; Nicol and Kennedy, 2008) and promote individual and collective empowerment (Cole et al., 1999; Lee, 2002; London, 2003; Buranatrevedh and Sweatsriskul, 2005; Orozco et al., 2009, Orozco and Cole, forthcoming).
The project of interest in this article, EcoSalud II, placed concerns about pesticides within a broad health and agricultural context. Its overall goal was to promote health as a resource for a quality life among small farm households in highland Ecuador. Specifically, it aimed to improve knowledge of highly hazardous pesticides (WHO toxicological classification of $\mathrm{Ib}$ and II, WHO, 2009) and practices related to pesticides and alternative crop management approaches. It was guided by a socio-ecological conceptual framework (McLeroy et al., 1988; Poole, 1997) which encompasses a range of theories on behavior change. Its framing was consistent with EcoHealth approaches emphasizing transdisciplinarity and participation (Lebel, 2003).

Here we focus on intermediate health promotion outcomes (Nutbeam, 1998), using a conceptual model of hypothesized relationships among important measured variables (Figure 1). Based on a qualitative study in two participating communities (Rubio, 2007), we highlighted local leadership and community interest in pesticide and human health issues as important influences on the intensity of community interventions. Individual education and household socio-economic status could modify awareness of alterative crop management options, knowledge of pesticide health risks and pesticide handling practices (Cole et al., 1997; Orozco et al., 2009). Community intervention intensity, individual participation in training and changes in household or individual awareness and knowledge should also be associated with household reduction in farm hazardous pesticide use. Note that changes in pesticide handling practices and changes in pesticides use might be independent outcomes, based on earlier work which showed far greater changes in the former than the latter (Cole et al., 2007).

\section{METHODS}

Evaluation design drew on community-based health promotion evaluation approaches (Russell et al., 1999; Merzel and D'Affliti, 2003). We used mixed methods, longitudinal design to examine both the implementation and impacts of EcoSalud II. 


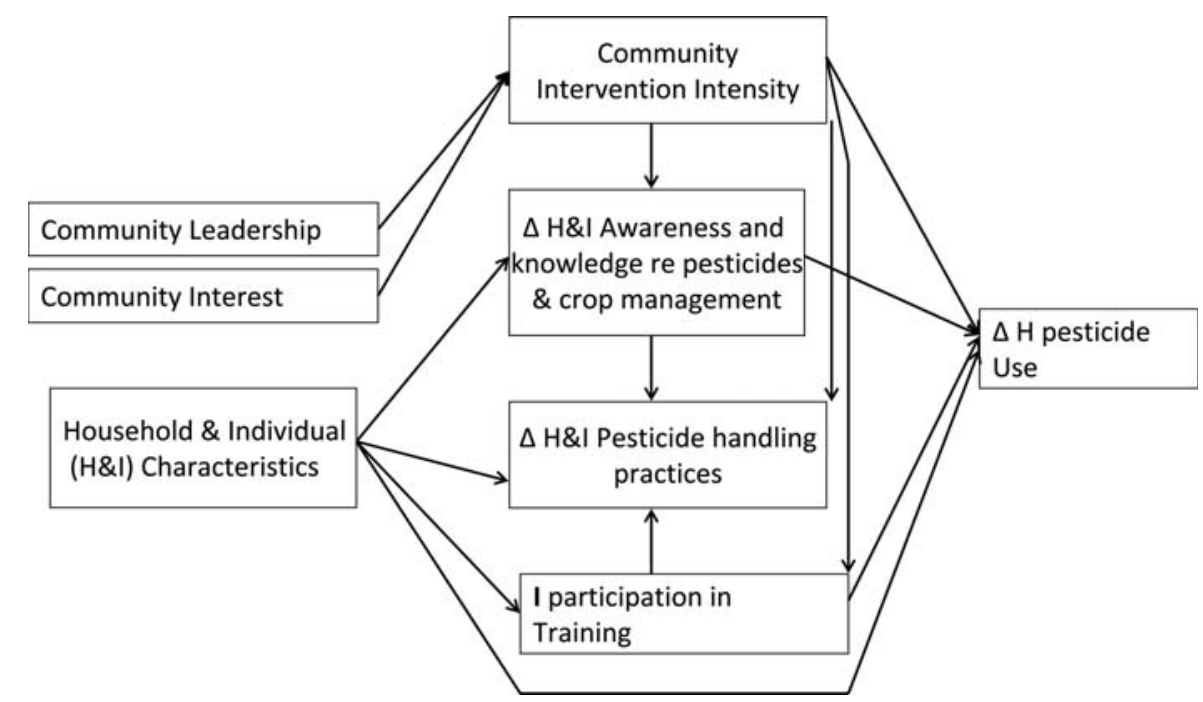

Fig. 1: Hypothesized paths linking community interventions with household and individual (H\&I) changes $(\Delta)$.

\section{Setting}

Adjacent, agricultural Andean provinces in south-central Ecuador were targeted: Tungurahua (canton of Quero) and Chimborazo (Guano, Guamote and Riobamba cantons). According to the national statistical authority's index of unsatisfied basic needs (necesidades básicas insatisfechas or NBI) (SIISE, 2008), 83.4\% of Guano's population, $86.8 \%$ of Quero's and $96.1 \%$ of Guamote's have been classified as poor. Riobamba canton includes the provincial capital with better infrastructure and services, so the overall poverty prevalence of $46.9 \%$ is lower, though higher among the rural population. Most of the population has mixed ethnic origins (mestizo), except for that in Guamote, where $92.6 \%$ are indigenous.

\section{EcoSalud II project team}

The intervention-research team was built up from the two first authors, and an agronomist affiliated with the International Potato Center (CIP), one of the CGIARs centers. [CGIAR: It is a strategic alliance of members, partners and international agricultural centers that mobilizes science to benefit the poor (http://www.cgiar. org).] We approached potential partner institutions (non-governmental and government organizations) active agricultural and or health development in the two provinces (for fuller description, see Orozco and Cole, forthcoming). Agronomists from these partner institutions supported the coordination, logistics and agricultural intervention components. Two female health education interns from the Polytechnic University of Chimborazo led the health intervention components in one province. The first author acted as overall coordinator. Figure 2 sets out the steps in project implementation.

\section{Community recruitment}

Agronomists from the partner institutions identified potential communities in which potatoes were the principal crop and small-scale farm households predominated. Contact was made with farmers which partner institutions had previously trained on crop management techniques. These agricultural promoters and other community leaders were canvassed on their interest in participating in a survey and interventions. General community meetings followed at which EcoSalud II general objectives were discussed.

\section{Time 1 survey}

Eighteen communities agreed to participate, 10 in Chimborazo and 8 in Tungurahua, in the time 1 survey from July to September 2005. In 


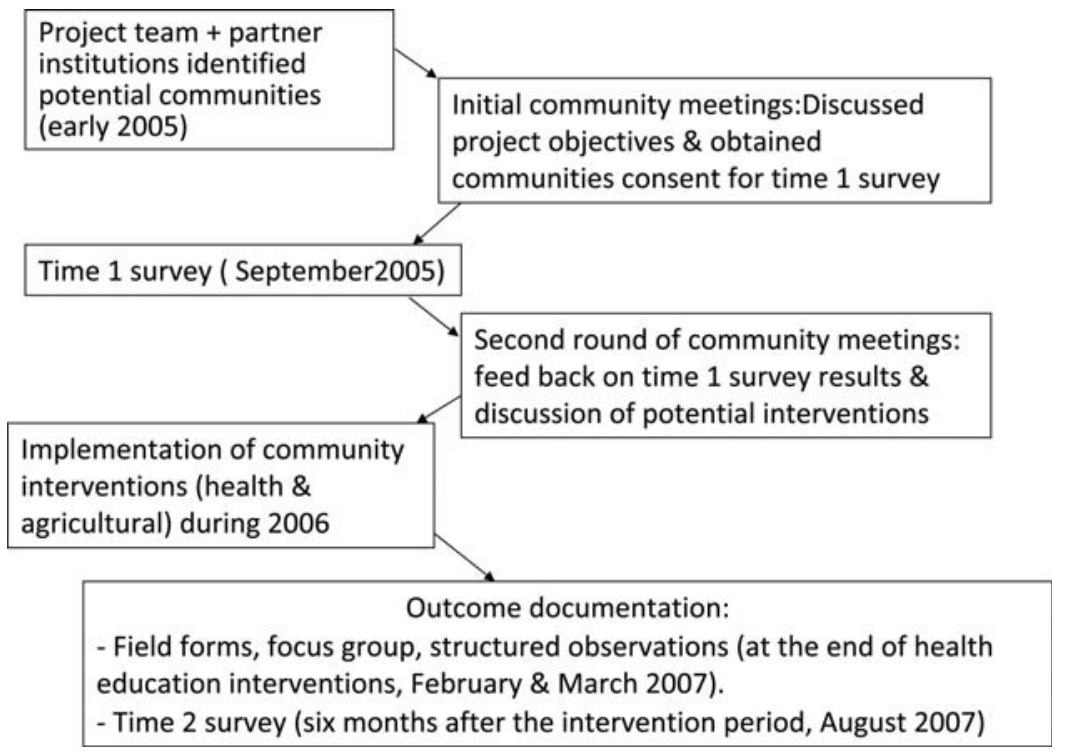

Fig. 2: Timeline of Ecosalud II project implementation.

each, $\sim 20$ volunteer households participated. Few households approached declined to participate but some had no-one present on repeat visits and some did not have two individuals meeting inclusion criteria or willing to complete each questionnaire (see below). Interest did vary across communities, so the final number of households per community ranged from 15 to 22 , with household response rate estimates from 70 to $95 \%$ per community. Inclusion criteria for individual participants were: between 18 and 65 years old, literate, lived in the community during the past 3 years, and were interested in participating in the research. In keeping with the Bioethics Committee of the National Health Council of Ecuador standards, this functions as a Research Ethics Board at national level. 'Community consent' was via the initial meetings with community leaders and then the general meeting with community members, i.e. that they had to consent as a community to participate. Individual participants consented in writing or verbally.

Different questionnaires were used for those responsible for managing crops (mostly men) or the home (mostly women). Drawing on questions from prior work (Yanggen et al., 2003), information on knowledge and practices regarding the use of pesticides, crop management, contamination pathways and ways in which information on pesticides was obtained, e.g. via training, was sought. To ensure the quality of information, a guide for collecting information was used, data collection was piloted prior to full roll out and the data collection team supervisor reviewed all surveys for completeness. Supplementary visits were made to clarify or revise incomplete or inaccurate data.

\section{Community interventions}

Based on survey results and agricultural promoter interest, the Ecosalud II project team generated a set of potential interventions. These were first presented to formal leaders of each community to obtain their support. Community meetings, attended by representatives from most families in the community, followed. The main descriptive results of the time 1 survey were presented and potential intervention activities proposed. After the communities agreed to participate, project team and community meeting attendees developed an implementation schedule for the period June 2006 to January 2007.

We adopted a radical model in designing our community interventions (Oliveira, 2005). We sought to: (i) encourage reflection among farm men and women on the personal reality of their farming practices and their health consequences; and (ii) stimulate joint identification of the causes of that reality and (iii) foster a 
collective search for responses. A particular focus were topics identified in prior CIP work (Yanggen et al., 2003), including information on colors of pesticide labels and their corresponding toxicity levels; pathways of pesticide contamination (Strong et al., 2009); symptoms of acute and chronic pesticide poisoning and subsequent treatment; and crop management techniques with an emphasis on 'Integrated pest management' (IPM). To complement community-based interventions, local radio stations (selected based on community leader surveys) were contracted to play radio spots to raise awareness. Three dialogues in Spanish or Kichwa (spoken by $79 \%$ of Chimborazo) aired three times a day, everyday for 6 months.

\section{Health education interventions}

In each community, interventions began with a theatrical introductory session followed by $\sim 7$ monthly health education sessions, lasting 60$90 \mathrm{~min}$ each. Educational techniques were chosen according to participants' preference, the subject matter and the expected audience for each session. Methods included puppets, socio-dramas, games, interactive exercises, drawings, forums, mural painting, relaxation exercises and body awareness sessions (more detailed descriptions in Arévalo et al., 2008). Puppet sessions were developed with school directors and teachers, and presented to parents and pupils. Other sessions were held at community centers or attached to 'mingas', collective work events such as road improvement. In communities with limited collaboration from leaders, sessions took place in farmers' fields or at the offices of the organization of potato producers.

\section{Agricultural interventions}

Agricultural promoters participated in a workshop to update their knowledge on alternative crop management and adequate pesticide handling practices. Along with agronomists, they facilitated farmer field schools (FFSs), workshops with FFS graduates, and field days. In the FFS, a group of 10-15 men and women farmers explored alternative crop management techniques over the 6-month potato crop cycle. Agricultural workshops were mainly for FFS graduates who belonged to the potato producers' organization. They consisted of $2-3 \mathrm{~h}$ every 2 weeks over 3 months ending with participants leading a field day. Prior announcements invited farmers from the region to participate in exhibits staged by FFS and workshop participants on alternative crop management and pesticide handling. In communities with a consolidated organizational structure, such as a potato farmers' organization, rotating funds worth 300 USD (the national currency) were set up. The organization purchased personal protective equipment (PPE) for pesticide application activities (worth $\sim 45$ USD) and gloves for washing used clothing. The revolving fund assisted organizations in promoting the use of PPE, and enabled the organization to sell PPE at or just above cost price. The organization then reinvested the earnings in the purchase of more PPE.

\section{Implementation and outcomes documentation}

We used both qualitative and quantitative data collection methods, including field forms, focus groups, structured observations and a repeat survey.

\section{Field forms}

For each health education session or agricultural intervention, health educators or agronomist documented the number of participants by gender, as well as observations on session proceedings and topics of interest which emerged in discussion.

\section{Focus groups}

During the final health education sessions in each community, participants were invited to take part in gender specific focus groups (36 in total), to be held in the following month. Inclusion criteria were: age 18-65, a farmer residing in the community, and participant in at least three health education sessions during the intervention period. Group sessions, between 10 and 15 participants, lasted about an hour and were recorded after obtaining consent from the participants. Two health educators were trained, one as a facilitator and one as a recorder, to lead the focus groups through a series of exercises on particular topics.

\section{Structured observations}

Following the focus groups, the same health educators undertook observations at two potato fields and two homes, randomly selected in each 
community (totals 36 each). The potato fields were visited during working hours and the homes after the workday. With farmers' consent, they made notes of their observations on a structured sheet including the use of PPE; types of pesticides used; pathways of contamination (disposal of packaging and pesticide remnants, eating habits during application); use of IPM practices; and signs of acute pesticide poisoning. In the homes, they observed: presence and washing of pesticide application clothing; storage of pesticides; location of work tools (pumps, buckets, spray tanks); and presence of used pesticides containers around the house.

\section{Repeat survey}

A time 2 survey was conducted in August 2007, 6 months after the intervention period, among the same households. Using time 1 field reports and databases with exact and working with people known in each community, we were able to localize 359 of the same households in time 2 . Those not included again at time $2(n=35)$ were most commonly due to household dissolution, individual migration out of the area, or the project team's persistent inability to locate a respondent. Questionnaires and data collection were similar to those in time 1 survey, with exclusion of some time 1 questions which had not turned out to be useful and addition of some response categories.

\section{Analysis \\ Qualitative analysis}

The EcoSalud II project team first developed a rating matrix for implementation of interventions in each community. Dimensions for rating were: (i) leadership support and coordination for health promotion activities (0, difficult; 1 , partial; 2, good); (ii) interest of community members in learning new things ( 0 , none; 1 , little; 2, some; 3, substantial); and (iii) agricultural and health interventions implemented $(0$, no; 1 , yes for each). Rating was conducted in a participatory way during a 1-day workshop. Each team member provided reasons for their ratings based on their experiences working with the community. Then other team members were asked regarding their agreement or disagreement with the statement. Discussion followed until a consensus was reached. Based on these indicators, communities were grouped into three categories of implementation: high, medium and low. High implementation communities were those with good leadership support, substantial interest of community members and most agriculture and health interventions carried out. Medium implementation communities were characterized as those with partial leadership support, some interest of community members, and where the agricultural and health interventions faced logistic and socio-organizational constraints. Low implementation communities were those where leadership support and coordination were difficult, there was none/or little interest of community members, and some of the interventions were only partially implemented, if at all. The material from focus groups and structured observations was organized in Excel according to these categories, participants' gender, and the province, with synthesis into salient themes.

\section{Quantitative analysis}

Community level variable construction. We used the community leadership and interest in learning new things as ordinal indicators (top left of Figure 1). For intervention intensity (middle top of Figure 1), aggregated indices were created to capture coverage and intensity for both descriptive and modeling purposes. The coverage index was the average of the percentage attendance for each intervention event, obtained from the field forms. The intensity index combined frequency and level of interventions. Frequency was classified as: 1, once, e.g. theater; 2 , once every 15 days over 3 months, e.g. agricultural workshops; 3, once every 15 days over 6 months, e.g. FFS; and 4, ongoing, e.g. revolving fund. Level was classified as: 1, community, e.g. field days, revolving funds, health education sessions and theater; 2 , groups where the attendees pertained to a farmers' association or were part of concentrated population sector such as schools; and 3 , individual, e.g. FFS.

Household/individual variable construction. For each household, we created an independent variable, household asset score, and a dependent variable, farm pesticide use. The former was constructed based on the main materials of the house, roof and floor; the number of rooms; the number of sleeping rooms; and the type of land ownership, having a score of 0 (low) to 10 (high). In the second 
questionnaire, we asked whether households had engaged in home improvements since 2005. Farm pesticide use was measured as the number of applications and active ingredient/application (weight in kilograms per hectare) during the most recent crop cycle. Hazardous pesticide type was classified according to the World Health Organization toxicological classification (WHO, 2009), with a focus on class Ib (highly hazardous) and class II (moderately hazardous), most of which were organophosphates or carbamates. The right-skewed distributions of pesticide use were transformed into deciles for modeling purposes.

Education was collapsed to 6 or more years and $<6$ years formal education. This was the only stable individual level variable. Knowledge of the color of pesticide labels and their corresponding toxicity (4 items) and knowledge of the symptoms associated with pesticide poisoning (14 items), both converted to a $0-10$ scale, were relevant for both household and crop managers. The crop managers' knowledge of IPM was dichotomous. Household manager practices included: whether clothes used for pesticide spraying were washed with gloves, whether they or other members entered recently sprayed fields, and adequacy of pesticide container disposal. Crop manager practices included: mixing technique, e.g. stirring with a stick, and spraying with the wind; and the use of PPE, e.g. gloves, plastic poncho or rubber pants. Each of the latter variables was converted to a 0-10 score.

Preliminary assessment of household/ individual-level change in awareness, practices and pesticide use (as per Figure 1). We calculated changes in continuous variables (or ordinal scales with sufficient breadth of distributions to be treated as continuous) and tested their significance using paired $t$-tests (all descriptive work with SAS version 9.3). For pesticide use deciles, we used the signed rank test. For dichotomus variables in which sufficient numbers of responses were available, we assessed the significance of changes using tests of symmetry for paired ordinal data (Agresti, 1990).

Modeling. For variable reduction, we checked intra-domain (within boxes of Figure 1) variable associations, by using cross-tabs for ordinal variables and correlations for continuous variables, and bivariate relationships between domains (across boxes of Figure 1), as preliminary tests of associations along the paths of interest from left to right. For hypothesized path testing, we conducted partial multivariable regressions linking boxes to the left in Figure 1 with the outcomes on the right. Variables which were not related to the outcomes could not be intermediary variables, e.g. training between community intervention variables and the change in handling practices or pesticide use (Baron and Kenny, 1986). Remaining variables were used in three sets of path models: for changes in knowledge and practices of the primary person managing the household and the primary person managing the crops, and for changes in pesticide use with both managers in the household. The rationale for the third combined model was that both managers may influence the choice of pest management approaches, based on their knowledge about pesticide-related hazards (Orozco et al., forthcoming). Numbers in each of these analyses were reduced: $n=323$ for household managers; $n=354$ for crop managers and combined model $n=673$.

We used MPLUS software Version 5.2 (Muthen and Muthen, 2008), which accommodates combinations of continuous and categorical mediating and outcome variables, and a weighted least squares method that produces robust standard errors and $\chi^{2}$ statistics. We reduced the path models by sequentially removing variables whose $z$-score was $<1.6$, roughly equivalent to $p=0.1$. We added paths as suggested by model modification indices in MPLUS, taking into account conceptual appropriateness. Fit was assessed on an iterative basis using the overall $\chi^{2}$ test, the Comparative Fit Index (CFI) and Tucker-Lewis Index (TLI) (for both high $>0.95$ is good, $\mathrm{Hu}$ and Bentler, 1999), the Root Mean Square Error of Approximation (RMSEA, low $<0.05$ is a close fit, Browne and Cudeck, 1993) and the weighted root mean-square residual (WRMR, >0.95 when $n \geq 250, \mathrm{Yu}, 2002)$. Unfortunately, the path model for crop managers had very poor fit, so we fell back onto a simpler regression model.

\section{RESULTS}

\section{Implementation}

Implementation was complete in eight high involvement communities, most $(n=5)$ of 
which were in Tungurahua. In these communities, leaders promoted project activities in a variety of ways and actively encouraged people to attend each activity. Hence community members were informed of project objectives and activities, increasing their interest and participation (Table 2). Good relationships were observed between leaders and members of the communities and coordination between these leaders and the project team was excellent.

It was easy to communicate with these leaders and they were open to project suggestions. In most cases, they had been formal leaders in earlier times and were recognized both by community members and agronomists, with whom they had worked before.

In seven medium involvement communities, five of these in Chimborazo, the health education interventions were completed but with lots of challenges: repeated postponements, cancellations due to limited attendance and delayed starting times. Overall fewer community members participated (Table 2). Similarly, agricultural interventions were incomplete (four Chimborazo communities) or were not implemented (two Tungurahua communities, one Chimborazo community). Although leaders of these communities seemed open and interested, they were often committed to other work and physically absent from their communities. This absence made coordination with the project team and involvement of community members difficult. Many community members were not informed of project activities nor did they know how they might participate.

In the two low involvement communities, one in each province, agricultural interventions were not implemented, and the theater was the only health education event in addition to radio spots which were accessible in all communities. Leaders of one community expressed greater interest in physical infrastructure support and had no interest in training. In the other, despite interest among some community members, the leaders refused collaboration with the project team. In a third Chimborazo community, health education interventions and some agricultural interventions were implemented through links with community members despite leaders' active discouragement. They scheduled other activities in the same places and times as project bookings, requiring considerable work in relocating and rescheduling project activities. Low participation may also have been due to

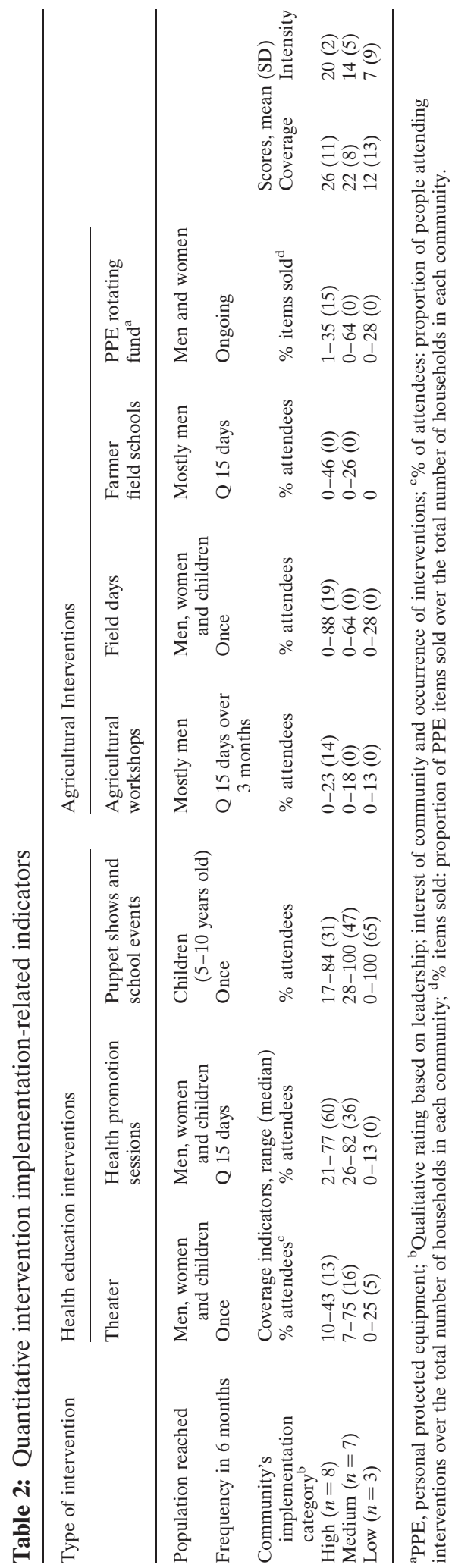


the fact that sessions were in Spanish while most community members spoke Kichwa. The impression of the research team was that these communities were also among the poorest, not discernable through parish level NBI statistical data (SIISE 2008).

\section{Descriptive outcomes}

\section{Pesticide-related knowledge and practices}

At time 1, the mean score for correct interpretation of pesticide labels was low among household managers (1.2) (over 10, a higher number means a better score and better knowledge) and even crop managers (2.6). Post intervention, greater proportions of both household managers and crop managers reported having received training (see Table 3 for household managers and Table 4 for crop managers). Important improvements in knowledge were found in several indicators, e.g. pesticide label reading increased significantly to 3.6 for household managers and 5.3 for crop managers. Crop managers' knowledge of the risk of pesticide contamination while mixing and spraying increased significantly between time 1 and 2 survey from 8.0 to 9.2 (Tables 3 and 4). The proportion of household managers using gloves for washing contaminated clothing increased from $15 \%$ at time 1 , to $22 \%$ at time $2(p=$ $0.0001)$. The use of protective equipment was generally low (mean 3.8/10 at time 1) but did improve significantly after the interventions (mean 4.3/10).

Qualitative differences in changes were observed according to community involvement in the interventions. For example, people in communities with no agricultural interventions and where theater was the only intervention generally failed to understand pesticide labels, with misinterpretation occurring more often among women. In these communities the only recognized pathway was wetting the skin of the hands and face. Farmers used a wider variety of pesticides and rarely used PPE.

Among communities with partial agriculture interventions, understanding of pesticide labels was more adequate. For example, a large proportion of men in Tungurahua, and women in Chimborazo indicated that lower hazard pesticides (WHO blue and green) can be handled

Table 3: Descriptive statistics of important individual and household variables for describing change between surveys, by domain [person who manages the household ( $n=359,356$ women and 3 men)]

\begin{tabular}{|c|c|c|c|}
\hline \multirow[t]{2}{*}{ Domain } & \multicolumn{2}{|l|}{ Time 2} & \multirow{2}{*}{$\begin{array}{l}\text { Significance based on } \\
\text { McNemar's test of symmetry }\end{array}$} \\
\hline & No & Yes & \\
\hline \multicolumn{4}{|l|}{ Dichotomous [\% (n)] } \\
\hline \multicolumn{4}{|l|}{ Training $(n=352)$} \\
\hline \multicolumn{4}{|l|}{ Time 1} \\
\hline No & $42 \%(147)$ & $44 \%(156)$ & \multirow{2}{*}{$p<0.0001$} \\
\hline Yes & $6 \%(21)$ & $8 \%(28)$ & \\
\hline \multicolumn{4}{|l|}{ Practices } \\
\hline \multicolumn{4}{|l|}{ Enter recently sprayed fields $(n=352)$} \\
\hline Time 1 & & & \\
\hline No & $38 \%$ (134) & $15 \%(52)$ & \multirow{2}{*}{$p=0.0018$} \\
\hline Yes & $26 \%(89)$ & $22 \%(77)$ & \\
\hline \multicolumn{4}{|l|}{ Wash clothes with gloves $(n=339)$} \\
\hline Time 1 & & & \\
\hline No & $32 \%(109)$ & $36 \%(122)$ & \multirow{2}{*}{$p<0.0001$} \\
\hline Yes & $11 \%(37)$ & $21 \%(71)$ & \\
\hline \multicolumn{4}{|l|}{ Container disposal less harmful $(n=352)$} \\
\hline \multicolumn{4}{|l|}{ Time 1} \\
\hline No & $8 \%(29)$ & $16 \%(57)$ & \multirow{2}{*}{$p=0.5637$} \\
\hline Yes & $14 \%(51)$ & $61 \%(215)$ & \\
\hline Domain & Time 1 & Time 2 & Significance \\
\hline \multicolumn{4}{|l|}{ Continuous [mean $(S D)]$} \\
\hline $\begin{array}{l}\text { Awareness and knowledge indicators }(0, \text { low }-10 \text {, high }) \\
(n=359)\end{array}$ & & & Paired $t$-test \\
\hline Label reading & $1.2(2.9)$ & $3.6(3.9)$ & $t=10.38, p<0.0001$ \\
\hline Symptom knowledge & $7.4(2.5)$ & $8.6(2.1)$ & $t=7.72, p<0.0001$ \\
\hline
\end{tabular}


Table 4: Descriptive statistics of important individual and household variables for describing change between surveys, by domain [person who manages the crops $(n=359,319$ men and 40 women)]

\begin{tabular}{|c|c|c|c|}
\hline \multirow[t]{2}{*}{ Domain } & \multicolumn{2}{|l|}{ Time 2} & \multirow{2}{*}{$\begin{array}{l}\text { Significance based on McNemar's } \\
\text { test of Symmetry }\end{array}$} \\
\hline & No & Yes & \\
\hline \multicolumn{4}{|l|}{ Dichotomous [\% (n)] } \\
\hline \multicolumn{4}{|l|}{ Training $(n=356)$} \\
\hline \multicolumn{4}{|l|}{ Time 1} \\
\hline No & $30 \%(106)$ & $42 \%(149)$ & \multirow{2}{*}{$p<0.001$} \\
\hline Yes & $8 \%(28)$ & $21 \%(73)$ & \\
\hline \multicolumn{4}{|l|}{$\begin{array}{l}\text { Awareness }(n=356) \\
\quad \text { integrated pest management }\end{array}$} \\
\hline Time 1 & & & \\
\hline No & $36 \%(126)$ & $38 \%(134)$ & \multirow[t]{2}{*}{$p<0.001$} \\
\hline Yes & $9 \%(31)$ & $18 \%(65)$ & \\
\hline Domain & Time 1 & Time 2 & Test for change $p$ value \\
\hline \multicolumn{4}{|l|}{ Continuous [mean $(S D)]$} \\
\hline Knowledge $(n=355)(0$ low-10 high $)$ & & & \multirow{6}{*}{$\begin{array}{l}\text { Paired } t \text {-test } \\
t=10.4, p<0.0001 \\
t=8.1, p<0.0001 \\
t=10.8, p<0.0001 \\
\text { Paired } t \text {-test } \\
t=4.5, p<0.0001\end{array}$} \\
\hline Label reading & $2.6(3.9)$ & $5.3(3.9)$ & \\
\hline Symptom knowledge & $7.7(2.3)$ & $9.0(2.0)$ & \\
\hline Contamination while mixing and spraying & $8.0(1.8)$ & $9.2(1.4)$ & \\
\hline Practice $(n=355)$ & & & \\
\hline $\begin{array}{l}\text { Personal protective equipment (PPE) use } \\
(0 \text { low }-10 \text { high })\end{array}$ & $3.8(2.0)$ & $4.3(1.8)$ & \\
\hline $\begin{array}{l}\text { Farm pesticide use }(n=359)(\mathrm{kg} / \text { crop cycle }) \text {, } \\
\text { median }(\mathrm{Q} 1, \mathrm{Q} 3)\end{array}$ & & & Signed rank test \\
\hline Ib: highly hazardous & $0.3(0,1.1)$ & $0.0(0,0.5)$ & $-8352.5, p<0.0001$ \\
\hline II: moderately hazardous & $0.1(0,0.6)$ & $0.0(0,0.1)$ & $-8949.5, p<0.0001$ \\
\hline
\end{tabular}

with greater confidence than those colored red (WHO extremely or highly hazardous) because they pose less risk to health and require fewer safety measures. In Chimborazo, most men listed pathways of exposure such as through storage within the home of application clothes, pesticides and working tools. No PPE use was apparent during field observations, and moderate symptoms were reported among the farmers observed. In Tungurahua, some farmers were observed wearing clothes used for applying pesticides and keeping pesticides and the tools used for mixing and application inside the home. The vast majority of women in these communities mentioned washing of contaminated clothes with the family's clothing as a pathway but none were observed wearing gloves for washing application clothing.

By contrast, in communities where all interventions were implemented, women generally expressed great concern about the health impact that pesticides have on their family. They considered it important to use protective gear when handling pesticides, regardless of color. Participants from these also recognized acute poisoning symptoms better and identified other symptoms such as fatigue, sleepiness and cramps. They also better recognized chronic symptoms: a large proportion of people mentioned pesticide effects on the nervous system with memory loss, personality changes and inability to perform basic math. The majority of men also recognized symptoms to be 'damaged nerves' and 'bad moods'. All communities mentioned cancer as a chronic effect of pesticides. Participants also mentioned wind and air as pathways of exposure. For example, women in these communities, especially in Chimborazo, noted that other people accompanying the farmers in the field during application could be exposed to pesticides. Field observations in these more complete implementation communities found that most pesticides used in communities were of lower toxicity; farmers tried to protect themselves and only mild symptoms of acute pesticide poisoning were observed. In most households, both pesticides and mixing and application tools were kept outside the home. The use of gloves for washing clothes was more frequently observed among these communities in Tungurahua. However, although the farmers of these communities of Chimborazo reported 
exposure pathways well, their handling of pesticides was generally unsafe.

\section{Awareness of and application of alternative crop management practices}

Awareness of IPM increased significantly, with $38 \%$ of crop managers who were unaware at time 1 reporting being aware at time 2 (versus only $9 \%$ which moved from yes to no) (Table 4). In general, people in Chimborazo were better informed about alternative crop management, though with differences in specific practices according to the level of community involvement in agriculture interventions. For example, in communities with no agriculture interventions, the most often mentioned techniques were the use of organic fertilizer, crop rotation and soil preparation. Participants in communities with partial or complete agriculture interventions, respectively, also mentioned the use of green and blue label pesticides, and the use of quality seeds. Structured observations corroborated these reports, with the use of practices that were associated with more training, such as insect traps, mainly used in these last communities.

\section{Community pressures to implement alternative crop management practices or use pesticides}

Health as a resource for living was one of the main positive pressures in more involved communities, with men in these communities also mentioning the importance of environmental preservation. In the less involved communities, most women thought IPM techniques made crops prone to pest infestations. Where leaders' support was better, men and women shared this perception and identified market pressures to ensure production as a main reason for widespread pesticide use. Further, strong negative social pressure was reportedly applied to those who applied IPM techniques or used protective clothing, with frank community mockery and criticism. A large proportion of men in the good leadership communities spoke of needing to 'see in order to believe' in the effectiveness of IPM practices. In these communities, especially in the province of Chimborazo, women mentioned that pressures to not attend training were exerted upon them or their husbands.

\section{Models}

The regression model for crop manager practices (not shown) included age, education, community leadership, training, change in knowledge and PPE use variables $\left(r^{2}=0.07\right)$. The only significant relationship was increased PPE use with more intense community interventions [intensity estimate $(\mathrm{SD})=0.10(0.03)]$.

The final path models showed excellent fit on the CFI, TLI and RMSEA (see bottom of Figures 3 and 4). WRMR values were less ideal ( 0.76 for household manager and 0.5 for both).

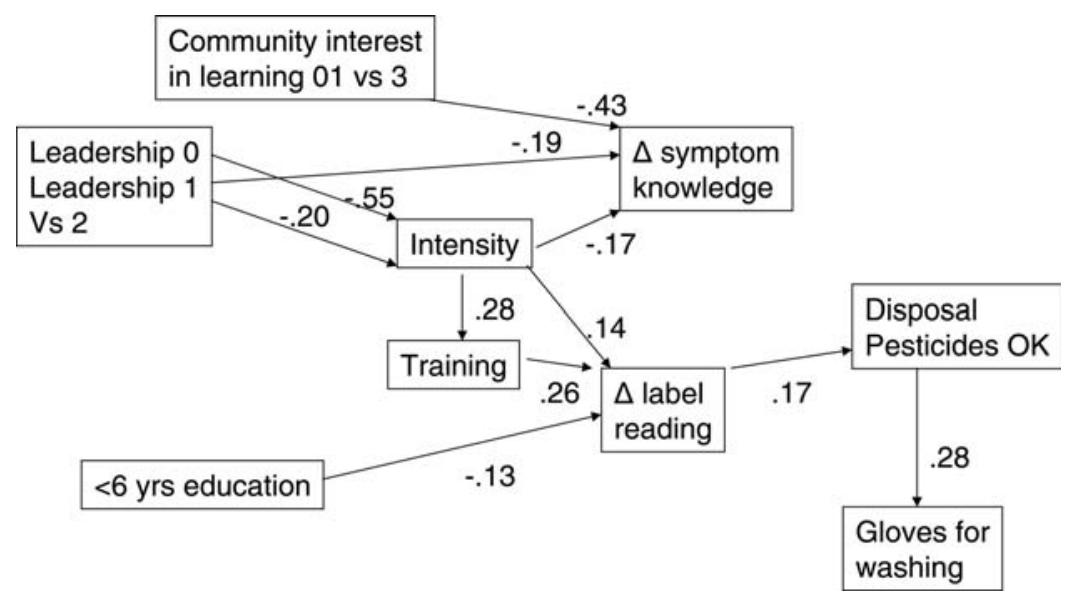

Fig. 3: Paths predicting changes in household managers' pesticide-related practices (significant standardized path coefficients). $\Delta$, Change, positive for symptom knowledge and label reading. All paths shown are $p<$ 0.05 . GofF indices: $\chi^{2} p=0.44, \mathrm{CFI}=\mathrm{TLI}=0.99, \mathrm{RMSEA}=0.007, \mathrm{WRMR}=0.76$. 


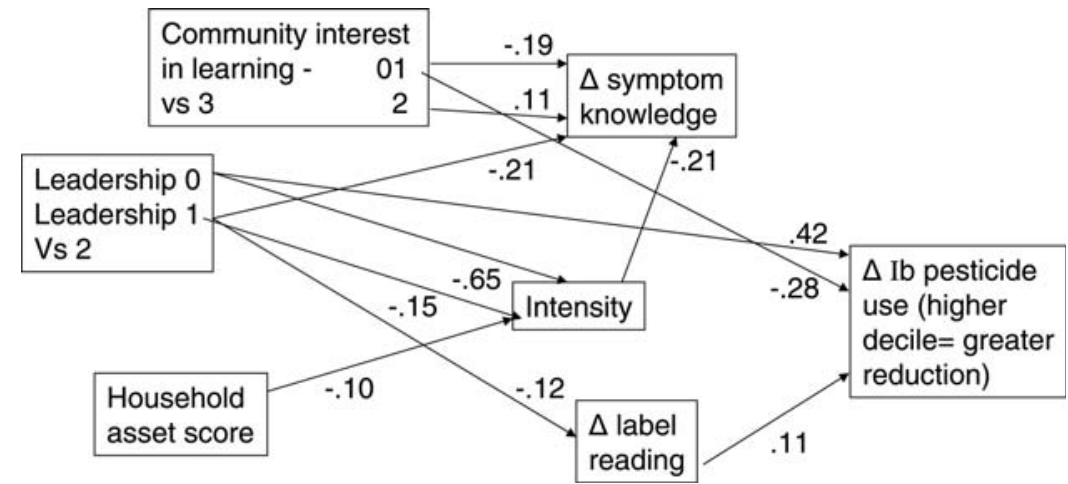

Fig. 4: Paths predicting changes in farm Ib pesticide use (crop and household managers) (significant standardized path coefficients). $\Delta$, Change, positive for symptom knowledge and label reading. All paths shown are $p<0.05$. GofF indices: $\chi^{2} p=0.7, \mathrm{CFI}=\mathrm{TLI}=1.0, \mathrm{RMSEA}=0.0, \mathrm{WRMR}=0.5$.

Significant paths $(p<0.05)$ were observed among household managers for practices (Figure 3) and among the two populations combined (household and crop managers) for farm pesticide use (Figure 4).

Across both models, poor community leadership was associated with reduced intensity of community interventions, with less training and less improvement in pesticide label knowledge. For the household manager, improved pesticide label knowledge was less in those with fewer than 6 years of education $(47 \%$ of household managers has $<6$ years in contrast to $68 \%$ of the crop managers), but improved with more intense community interventions and greater training. This improved label reading was associated with better pesticide container disposal practices, which in turn was associated with the use of gloves for washing pesticide application clothes (despite the lack of significant change on bivariate analysis in disposal, model fit was better with these variables included). The over-riding influence inhibiting changes in symptom knowledge was a community's lack of interest in learning new things, followed by less active leadership in the community.

Among both crop and household managers, training was more common among those with less education and those managing crops, perhaps reflecting the greater proportion of lower educated men among the crop managers. Community interest continued to play a role, i.e. less interest associated with less improvement in knowledge. No leader support was associated with less intensity of interventions, less change in label reading and less reduction in pesticide use. The fact that no support was also directly associated with more reduction in $1 \mathrm{~b}$ pesticide use may reflect the decline in resources for buying pesticides among poor communities during difficult economic times.

\section{DISCUSSION}

In this mixed method evaluation, we found that changes in some knowledge, practice and use indicators were associated with the intensity of community interventions. These, in turn, were associated with the extent of community leadership or community member interest in learning. Weaknesses in social organization and lack of community leader empowerment have been described as important factors impeding implementation, impacts and sustainability of health education, agricultural extension and environmental improvement programs (McLeroy et al., 1988; Cernea, 1995; Butterfoss et al., 1996; Buranatrevedh and Sweatsriskul, 2005; Dressendorfer et al., 2005; Rubio, 2007). Differences in community leadership led to different learning opportunities for community members about pesticide adverse health effects and more adequate crop management practices, particularly for household managers.

Unlike many occupational health and safety education programs oriented primarily to crop managers, our community-oriented health promotion programs included more farm members, similar to farm safety programs in other parts of the world, e.g. in Ontario, Canada, the Farm Safety Association (see 
www.farmsafety.ca/pages/children_justforkids. html). Involvement of all those exposed to pesticides through multiple pathways (Peres et al., 2006) is important for going beyond intrapersonal factors to achieve collective shifts in communities (Austin et al., 2001; Cole et al., 2002; Buranatrevedh and Sweatsriskul, 2005; Quandt et al., 2006; Nicol and Kennedy, 2008; Strong et al., 2008; Arcury et al., 2009). As in other contexts where participation of women in crop management training has required links with community organizations (Hamilton et al., 2003), EcoSalud II explicitly addressed such potential barriers to participation by choosing convenient times for activities. The greater involvement of women, the majority of household managers, promoted their learning about pesticides and alternatives. This in turn appeared to influence collective understanding of hazards and options in agricultural practices and their health implications, in keeping with population approaches (Cohen et al., 2000).

The limited differences in observed individual behavior, despite changes in reported knowledge, may be due to a range of other unmeasured and structural factors. In keeping with other research, the poverty of these rural households meant that purchase of effective PPE such as gloves may be beyond their means (Yanggen et al., 2003). Restrictive cultural norms against wearing PPE, e.g. machismo, likely also plays a role (Orozco et al., 2009; Feola and Binder, 2010). Further, as Rubio (Rubio, 2007) noted, despite knowledge about the hazards associated with pesticide use, farmers considered their use to be a necessary evil required for their survival.

Our difficulty in explaining crop managers' reported changes in practices with the set of individual, household and community factors included in our hypothesized model, likely reflects the role of other relevant factors (McLeroy et al., 1988; Poole, 1997). Market conditions, particularly the need to guarantee flawless produce for good prices, strongly influences crop management decisions (Buranatrevedh and Sweatsriskul, 2005; Palis et al., 2005; Galt, 2008; Rodriguez et al., 2008; Orozco et al., 2009). Needed are programs which reduce the availability of highly hazardous products (Jansen, 2008), which work with farmers to test and implement alternative integrated crop management approaches in extension programs (Galt,
2008), and which more generally improve the living conditions of and services available to rural populations.

In terms of rigor, our evaluation experienced community and household self-selection biases which many health promotion initiatives face. Involvement by enthusiastic volunteers can tend to over-estimate generalizable impacts on health promotion outcomes. However, the fact that some communities were less involved created the contrast necessary to show differences across communities by the extent of leadership and intensity of implementation. Further, the inter-sectoral (agriculture, environment and health) design, implementation and content of the interventions were in keeping with the nature of social dynamics in Andean agriculture (Ledezma, 2006). The interventions reflected accepted social theories of change as advocated by leaders in health promotion (Potvin et al., 2005). Additional research, observing communities for longer periods to assess social dynamics and sustainability of any changes over time, would contribute to our understanding of how to more effectively promote changes in agricultural practices that can benefit the health of humans and their ecosystems.

\section{FUNDING}

International Development Research Centre (IDRC) Ecosystem Health Initiative \#101810-001 to the International Potato Center.

\section{REFERENCES}

Agresti, A. (1990) Categorical Data Analysis. Wiley, New York.

Arcury, T. A., Marin, A., Snively, B. M., Hernández-Pelletier, M. and Quandt, S. A. (2009) Reducing farmworker residential pesticide exposure: evaluation of a lay health advisor intervention. Health Promotion Practice, 10, 447-455.

Arévalo, J., Guaman, L., Orozco, F. and Cole, D. C. (2008) Aprendiendo con nuestra gente: Actividades de Promoción y Educación en Salud para disminuir los Riesgos y Contaminación por Pesticidas. Proyecto Ecosalud. Centro Internacional de la Papa. Quito, Ecuador.

Austin, C., Arcury, T. A., Quandt, S. A., Preisser, J. S., Saavedra, R. M. and Cabrera, L. F. (2001) Training farmworkers about pesticide safety: issues of control. Journal of Health Care for the Poor and Underserved, 12, 236-249. 
Bantilan, M. C. S. and Padmaja, R. (2008) Empowerment through social capital build-up: gender dimensions in technology uptake. Experimental Agriculture, 44, 61-80.

Baron, R. M. and Kenney, D. A. (1986) The moderatormediator variable distinction in social psychological research: conceptual, strategic, and statistical considerations. Journal of Personality and Social Psychology, 51, 1173-1182.

Browne, M. W. and Cudeck, R. (1993) Alternative ways of assessing model fit. In Bollen, K. A. and Long, J. S. (eds), Testing Structural Equation Models, Sage, Newbury Park, CA, pp. 136-162.

Buranatrevedh, S. and Sweatsriskul, P. (2005) Model development for health promotion control of agricultural occupational health hazards and accidents in Pathumthani, Thailand. Industrial Health, 43, 669-676.

Butterfoss, F. D., Goodman, R. M. and Wandersman, A. (1996) Community coalitions for prevention and health promotion: factors predicting satisfaction, participation and planning. Health Education Quarterly, 23, 65-79.

Cernea, M. M. (1995) Social organization and development anthropology. Human Organization, 54, 340-352.

Cohen, D. A., Scribner, R. A. and Farley, T. A. (2000) A structural model of health behavior: a pragmatic approach to explain and influence health behaviors at the population level. Preventive Medicine, 30, 146-154.

Cole, D. C., Carpio, F., Julian, J., Leon, N., Carbotte, R. and de Almeida, H. (1997) Neurobehavioral outcomes among farm and nonfarm rural Ecuadorians. Neurotoxicology and Teratology, 19, 277-286.

Cole, D. C., Gibson, J. and Ross, N. (1999) Link between humans and ecosystems: the implications of framing for health promotion strategies. Health Promotion International, 14, 65-72.

Cole, D. C., Sherwood, S., Crissman, C., Barrera, V. and Espinosa, P. (2002) Pesticides and health in highland Ecuadorian potato production: assessing impacts and developing responses. International Journal of Occupational and Environmental Health, 8, 182-190.

Cole, D. C., Sherwood, S., Paredes, M., Sanin, L. H., Crissman, C. H., Espinosa, P. et al. (2007) Reducing pesticide exposure and associated neurotoxic burden in an Ecuadorian small farm population. International Journal of Occupational and Environmental Health, 13, 281-289.

Crissman, C., Antle, J. M. and Capalbo, S. M. (eds) (1998) Quantifying Tradeoffs in the Environment, Health and Sustainable Agriculture: Pesticide Use in the Andes. Kluwer Academic Press, Boston.

Dressendorfer, R. H., Raine, K., Dyck, R. J., Plotnifoff, R. C., Collins-Nakoi, R. L., McLaughlin, W. K. et al. (2005) A conceptual model of community capacity development for health promotion in the Alberta Heart Health Project. Health Promotion Practice, 6, 31-36.

Erbaugh, J., Donnermeyer, J., Amujal, M. and Kyamanya, S. (2003) The role of women in pest management decision making in Eastern Uganda. Journal of International Agricultural and Extension Education, 10, 71-82.

Feola, G. and Binder, C. (2010) Why don't pesticide applicators protect themselves? Exploring the use of personal protective equipment among Colombian smallholders. International Journal of Occupational and Environmental Health, 16, 11-23.

Galt, R. E. (2008) Toward an integrated understanding of pesticide use intensity in Costa Rican vegetable farming. Human Ecology, 36, 355-377.
Hamilton, S., Moore, K., Harris, C., Erbaugh, J., Tanzo, I., Sachs, C. et al. (2003) Gender and IPM. In Norton, G., Heinrichs, E. A., Luther, G. C. and Irwin, M. E. (eds), Globalizing Integrated Pest Management, Blackwell Publishing, Iowa, pp. 263-289.

Hruska, A. J. and Corriols, M. (2002) The impact of training in integrate pest management among Nicaraguan maize farmers: increased net returns and reduced health risk. International Journal of Occupational and Environmental Health, 8, 191-199.

$\mathrm{Hu}$, L. and Bentler, P. M. (1999) Cutoff criterion for fit indexes in covariance structure analysis: conventional criteria versus new alternatives. Structural Equation Modeling, 6, 1-55.

Janhong, K., Lohachit, Ch., Butraporn, P. and Pansuwan, P. (2005) Health promotion program for the safe use of pesticides in Thai farmers. Southeast Asian Journal of Tropical Medicine and Public Health, 36, 258-261.

Jansen, K. (2008) The Unspeakable Ban: the translation of global pesticide governance into Honduran national regulation. World Development, 36, 575-589.

Keifer, M. C. (2000) Effectiveness of interventions in reducing pesticide overexposure and poisonings. American Journal of Preventive Medicine, 18, 80-89.

Konradsen, F., van der Hoeck, W., Cole, D. C., Hutchinson, G., Daisley, H., Singh, S. et al. (2003) Reducing acute poisoning in developing countriesoptions for restricting the availability of pesticides. Toxicology, 192, 249-261.

Lebel, J. (2003) Health and Ecosystem Approach. International Development Research Centre, Ottawa, ON, pp. 1-24. http://www.idrc.ca/ecohealth.

Ledezma, J. (2006) Género, Trabajo Agrícola y Tierra. AbyaYala \& Centro de Comunicación y Desarrollo Andino (CENDA). PrimeraEdición, Quito, Ecuador, pp. 183.

Lee, Ch. (2002) Environmental justice: building a unified vision of health and the environment. Environmental Health Perspectives, 110, 141-144.

London, L. (2003) Human rights, environmental justice, and the health of farm workers in South Africa. International Journal of Occupational and Environmental Health, 9, 59-68.

Luther, G., Harris, C., Sherwood, S., Gallagher, K., Mangan, J. and TouréGamby, K. (2005) Developments and innovations in farmer field schools and the training of trainers. In Norton, G. et al. (eds), Globalizing Integrated Pest Management, Blackwell Publishing, Iowa, pp. $159-172$.

Mancini, F., Jiggins, J. L. and O'Malley, M. (2009) Reducing the incidence of acute pesticide poisoning by educating farmers on pest management in south India. International Journal of Occupational and Environmental Health, 15, 143-151.

McLeroy, K. R., Bibeau, D., Steckler, A. and Glanz, K. (1988) An ecological perspective on health promotion programs. Health Education \& Behavior, 15, 351-377.

Merzel, Ch. and D'Afflitti, J. (2003) Reconsidering community based health promotion: promise, performance and potential. American Journal of Public Health, 93, $557-574$.

Murray, D. L. and Taylor, P. L. (2000) Claim no easy victories: evaluating the pesticide industry's global Safe Use campaign. World Development, 28, 1735-1749.

Muthen, B. and Muthen, L. (1998-2009) Mplus User's Guide, 5th edition. Muthen \& Muthen, Los Angeles, CA. 
Nicol, A. M. and Kennedy, S. M. (2008) Assessment of pesticide exposure control practices among men and women on fruit-growing farms in British Columbia. Journal of Occupational and Environmental Hygiene, 5, 217-226.

Nutbeam, D. (1998) Evaluating health promotion-progress, problems and solutions. Health Promotion International, 13, 27-44.

Oliveira, D. L. (2005) A 'nova' saúde pública e a promoção da saúde via educação: entre a tradição e a inovação. Revista Latino-Americana de Enfermagen, 13, 423-31.

Orozco, F. and Cole, D. C. (forthcoming) Tackling challenges to farmers' health and agro-ecosystem sustainability in highland Ecuador. In Charron, D. (ed), Ecohealth, IDRC, Ottawa, Canada.

Orozco, F., Cole, D. C. and Muñoz, F. (forthcoming) Gender relations and pesticide-related knowledge, crop management practices, and health status among small farmers in highland Ecuador. International Journal of Environmental Health.

Orozco, F., Cole, D. C., Forbes, G., Kroschel, J., Wanigaratne, S. and Arica, D. (2009) Monitoring adherence to the International Code of Conduct: highly hazardous pesticides in central Andean agriculture and farmers' Rights to Health. International Journal of Occupational and Environmental Health, 15, 255-269.

Palis, F. G., Morin, S. and Hossain, M. (2002) Social capital and diffusion of integrated pest management technology: a case study in Central Luzon, Philippines, Social Research Conference, September 11-14, CIAT, Cali, Colombia.

Palis, F. G., Morin, S. and Hossain, M. (2005) Social capital and geography of learning: Roles in accelerating the spread of integrated management. Journal of Agricultural Education and Extension, 11, 27-37.

Peres, F., Moreira, J., Rodriguez, K. and Claudio, L. (2006) Risk perception and communication regarding pesticide use in rural work. A case study in Rio de Janeiro State, Brazil. International Journal Occupational and Environmental Health, 12, 400-407.

Perry, M. and Layde, P. M. (2003) Farm pesticides: outcomes of a randomized controlled intervention to reduce risks. American Journal of Preventive Medicine, 24, 310-315.

Poole, D. L. (1997) Building community capacity to promote social and public health: challenges for universities. Health and Social Work, 22, 163-170.

Potvin, L., Gendran, S., Bilodeau, A. and Chabot, P. (2005) Integrating social theory into public health practice. American Journal of Public Health, 95, $591-595$.
Quandt, S. A., Hernández-Valero, M. A., Grzywacz, J. G., Hovey, J. D., Gonzales, M. and Arcury, T. (2006) Workplace, household, and personal predictors of pesticide exposure for farm workers. Environmental Health Perspectives, 114, 943-952.

Roberts, D., Karunarathna, A., Bucley, N., Manuweera, G., Rezvi, M. H. and Eddleston, M. (2003) Influence of pesticide regulation on acute poisoning deaths in Sri Lanka. Bulletin of the World Health Organization, 81, 789-798.

Rodriguez, J. M., Molnar, J. J., Fazio, R. A., Sydnor, E. and Lowe, M. J. (2008) Barriers to adoption of sustainable agriculture practices: change agent perspective. Renewable Agriculture and Food Systems, 24, 60-71.

Rubio, F. M. P. (2007) Health education and collective action: a case study in the Central Ecuadorian Andes. A research essay submitted to The Faculty of Graduate Studies and Research in partial fulfilment of the requirements for the degree of Master of Arts. The Norman Paterson School of International Affairs, Carleton University, Ottawa, Ontario.

Russell, E., Vogt, T. M. and Boles, S. M. (1999) Evaluating the public health impact of health promotion interventions: the RE-AIM framework. American Journal of Public Health, 89, 1322-1327.

SIISE, Ecuador. (2008) Sistema Integrado de Indicadores Sociales del Ecuador. Ministerio de Coordinación de Desarrollo Social.

Strong, L., Starks, H., Meischke, H. and Thompson, B. (2009) Perspectives of mothers in farmworker households on reducing the take-home pathway of pesticide exposure. Health Education and Behavior, 36, 915-929.

Strong, L., Thompson, B., Koepsell, T. and Meischke, H. (2008) Factors associated with pesticide safety practices in farm workers. American Journal of Industrial Medicine, 51, 69-81.

World Health Organization (WHO) (2009) The WHO Recommended Classification of Pesticide by Hazard and Guidelines to Classification. WHO, Geneva, Switzerland.

Yanggen, D., Crissman, C. and Espinoza, P. (eds). (2003). Los Plaguicidas, Impactos En Producción, Salud y Medio Ambiente en Carchi, Primera Ed. CIP, INIAP \&AbiYala, Quito, Ecuador.

$\mathrm{Yu}$, C. Y. (2002). Evaluating cutoff criteria of model fit indices for latent variable models with binary and continuous outcomes. Dissertation, Doctor of Philosophy in Education, University of California, Los Angeles, CA, pp. 154-155. 